\title{
A Method for Estimating the Participation Rate of Elder Care
}

\author{
Ben David Nissim, Halperin Daphna, Kats Ruth, Lowenstein Ariela, Tur Sinai Aviad \\ Emek Yezreel Academic College, Emek Yezreel, Israel \\ Email:nissimb@yvc.ac.il, dafnah@yvc.ac.il, ruth@soc.haifa.ac.il, ariela@research.haifa.ac.il, \\ avts2309@013net.net
}

Received 13 May 2016; accepted 6 June 2016; published 9 June 2016

Copyright (C 2016 by authors and Scientific Research Publishing Inc.

This work is licensed under the Creative Commons Attribution International License (CC BY).

http://creativecommons.org/licenses/by/4.0/

\section{c) (i) Open Access}

\begin{abstract}
This paper focused on estimating the participation rate of care giving to elders. We used a theoretical model frame that was in common use for analyzing activity in the labor market and adjusted it for analyzing the care giving rate in elders. Using data of the rate of start taking care and the rate of end taking care in elders from the Survey of Health, Aging and Retirement in Europe we evaluated the rate of "caregivers" in whole population at age over 50 and among males, females, people in labor force and out of labor force. According to our results, the lowest care rate is among men $16.8 \%$, and the highest is among females $18.88 \%$, while for whole population at age over 50 , the care rate is $\mathbf{1 8 . 2 \%}$. According to our findings, there is a very high end of care rate from treatment in all population groups, pointing to the existence of a very large substitution among caregivers, mainly among people not in labor force $(76.2 \%)$.
\end{abstract}

\section{Keywords}

\section{Elders Care, Substitution in Care}

\section{Introduction}

Given global population aging and increased longevity, the oldest old (over 85) is the fastest-growing segment, and so family care has become a near universal experience (WHO, 2002) [1]. With constraints on state spending, long-term elder care has become a major issue for both families and states. Informal caregivers (spouses and/or adult children and other relatives) comprise $90 \%$ of the in-home long-term-care needed, the majority of which is for the elderly.

By 2014, Israeli society comprised about 8.7 million people, among them $10 \%, 870,000$, were aged over 65 and older (Brodskym Shnoor \& Béer, 2014) [2]. The care givers may start and end care several times, both for 
the same care recipient as well as for different recipients, e.g., parental care followed by spousal care (Lowenstein, Katz \& Gur-Yaish, 2008) [3]. These fluctuations might be due to an elder's death or changes in the flows of members in and out of caregiving, as well as the flow of new people becoming old and frail and so in need of care.

In order to improve our understanding of the state of care givers, we suggest concentrating attention on two groups: the first is elders in need of care and the second is people who potentially can take care of the first group.

Figure 1 presents the status of these two groups.

Assuming that each elder is taken care of by one care giver ${ }^{1}$, group $2 \mathrm{a}$ and la are identical.

In this paper, we intend to evaluate the rate of individuals aged over 50 who give care to elders (group 2a in Figure 1). The tendency to take care of someone, $u_{t}$, will be defined as the rate of members who are taking care of someone out of the total number of members at age 50 and above ${ }^{2}$.

The change in the rate of elder care according to the flows in and out of care largely resembles the process that changes the rate of unemployment in the labor market. In this paper, we use a frame of a model that has already been used by economists for estimating the main factors affecting the labor market. The matching function model with two-sided search (developed by Pissarides (1984) [4], Mortensen (1982) [5], Diamond (1982) [6] and others) is central to the theoretical literature on labor market flows. The main innovation in those papers is that market frictions are modeled by an exogenously given matching function that relates the number of matches per unit of time to the stock of workers and the firms engaged in searching. The matching function thus captures the technology that brings people together in the market. The separation rate from employment, as well as the growth rate of the labor force, together with the matching rate of unemployed workers, determines the unemployment rate.

Assuming that transition probabilities in and out of care are determined endogenously (but are also affected by exogenous changes), we can apply the basic frame of the search model in order to estimate the rate of care giving for elders.

\section{The Equilibrium of the Transition Probabilities}

\subsection{The Model}

\section{The Matching Function}

Elders needing care and potential caregivers are matched with each other according to prevailing matching technology. We assume that the number of matches formed at any moment of time is a well-behaved function of the economic, social, and health characteristics of the elder and of the potential care givers. In steady state, one flow persists out of the stock of "members who are caregivers" and one flow in. The flow out is due to the destruction of existing matches and the flow of dying elders and the flow in is the number of elders who are matched to new care givers.

There are $\mathrm{L}$ homogeneous number of potential care givers and let $\mathrm{u}_{\mathrm{i}}$ denote the rate of "members who are taking care of someone".

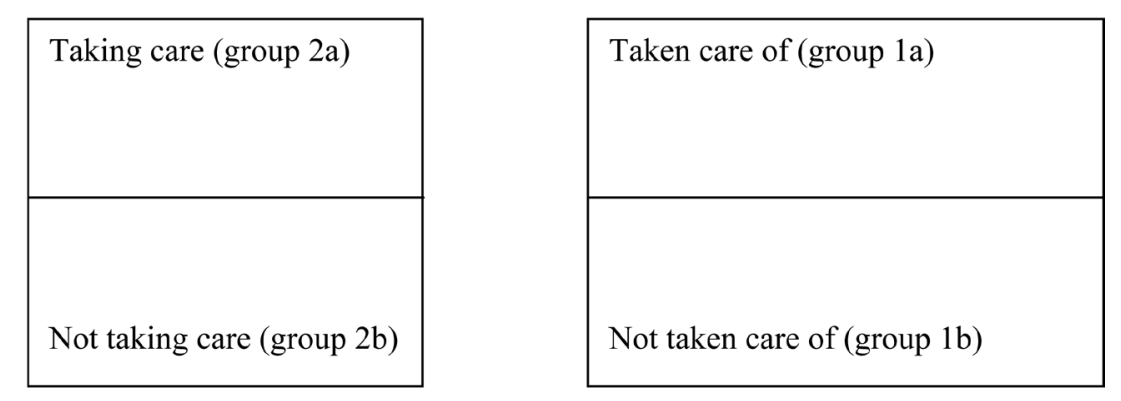

Figure 1. Potential care givers and elders in need of care.

\footnotetext{
${ }^{1}$ In a situation where several people take care of the same elder, the size of these two groups will not be the same.

${ }^{2} u_{t}=\frac{\text { group } 2 \mathrm{a}}{\text { group } 2 \mathrm{a}+\text { group } 2 \mathrm{~b}}$.
} 
The probability of new match, $q_{t}$ at any period of time $\mathrm{t}$ between care givers and elders is given by:

$$
q_{t}=x_{t}\left(L_{t}^{j}, K_{t}^{m}\right) \text { for } j=1,2, \cdots ; m=1,2, \cdots
$$

where

$L_{t}^{j}$ for $j=1,2, \cdots$ are attributes of the elders in time $t$;

$K_{t}^{m}, m=1,2, \cdots$ are attributes of the care givers in time $t$.

Given elders' and potential caregivers' attributes, the matching function, (1) defines the probability that a new match will occur.

We assume that the end of care rate from a match, $\mathrm{S}_{\mathrm{t}}$, is defined by (2):

$$
S_{t}=y_{t}\left(L_{t}^{z}, K_{t}^{p}\right) \text { for } z=1,2, \cdots ; p=1,2, \cdots
$$

where

$L_{t}^{z}$ for $z=1,2, \cdots$ are attributes of the elders in time $t$;

$K_{t}^{p}, p=1,2, \cdots$ are attributes of the caregivers in time $t$.

Let the natural rate of growth of the potential care givers be $n^{3}$ and let us define:

$u_{t}$ : the rate of members who are taking care of someone out of the total number of potential care givers ${ }^{4}$;

$L_{t}$ : the total number of potential care givers.

We get that $u_{t} L_{t}$ is the total number of individuals who take care of elders while $\left(1-u_{t}\right) L_{t}$ is the total number of individuals who do not take care of elders in need of care.

Given that $S_{t}$ represent the rate of end of care between elders and caregivers, the total number of separations is $S_{t} u_{t} L_{t}$, while the number who enter the group of caregivers during this time is $q_{t}\left(1-u_{t}\right) L_{t}$.

In steady state, the mean rate of caregivers $\left(u_{t}\right)$ is constant, so that the flows into a state of "care giving" minus the flow out of this state must represent a growth rate that equals the rate of growth of the potential caregiver group and we get:

$$
\frac{q_{t}\left(1-u_{t}\right) L_{t}-S_{t} u_{t} L_{t}}{u_{t} L_{t}}=n_{t}
$$

Rearranging Equation (3), in steady state, the rate of "caregivers" is determined in equilibrium as a function of the natural growth rate the population of the potential caregivers, the end of care rate, and the probability that a new match will occur between a caregiver and an elder:

$$
u_{t}=\frac{q_{t}}{q_{t}+s_{t}+n_{t}}
$$

\section{Empirical Analyses}

The current study is based on data from the first two waves of SHARE-Israel, tracking the provision of support by persons aged over 50 from the population interviewed in both waves (hereinafter: the traced population).

The Survey of Health, Aging and Retirement in Europe (SHARE) is a longitudinal survey launched more than ten years ago to study Europe's changing demographic trends. SHARE-Europe seeks to better understand the dynamics of the growing population of persons aged over 50. In addition, it aims to provide a research infrastructure for public policy making on behalf of the aging population. Its data provides a unique way to compare the economic situation, health, and welfare of older people in different European countries over time. Twenty countries across Europe have taken part thus far (including Israel) and over 85,000 men and women aged 50+ and their spouses have been interviewed. Israel joined the SHARE project in 2005 and has participated in the first wave (2005-2006) which queried more than 2500 respondents and the second wave (2009-2010) which canvassed a similar number. The traced population numbers 1710 respondents, of whom 1250 are aged 50 - 69 . The Wave 1 interviews took place between September 2005 and August 2006.

The respondents were asked, among other things, whether they had provided any individual (household

${ }^{3}$ In defines the net growth, i.e. new members joining the potential care givers group minus the number of deaths in the group.

${ }^{4}$ In this paper, we assume that each agent at age over 50 is a potential care giver. 
member or otherwise) at least one of the following three types of assistance in the preceding twelve months: 1) personal help in matters such as dressing, bathing or showering, feeding, getting out of bed, and using the toilet; 2) practical household help such as repairs, taking care of the garden, transport, shopping, and housework; 3 ) help with paperwork, e.g., filling out forms or settling financial or legal affairs. The Wave 2 interviews were conducted between August 2009 and August 2010; the interval between the interviews in the two waves ranged from thirty-seven months to fifty-seven months. The descriptive statistics of the transitions among support-caregiving situations are based on weights of households in Wave 1. Respondents' self-reportage about having provided support includes the following situations: "gave support" relates to a person who reported having another person (member of household or otherwise) providing at least one of the following three types of support in the preceding twelve months: personal care, practical household help, or help with paperwork. "Did not give support" relates to a person who reported not having given any person (household member or otherwise) at least one of the aforementioned three types of assistance in the preceding twelve months.

Using the longitudinal SHARE-Israel data base, we calculated the proportion of individuals who were taking care of an elder in wave 1, but did not take care of anyone in wave 2 and the proportion of individuals who did not take care of elders in wave 1 , but started to take care of an elder in wave 2.

Table 1 presents the proportions according to certain attributes and demographic characteristics of the survey population.

According to the results presented in Table 1, the end of care rate (destruction of matches) for the total population of care givers is $s_{t}=0.696$ while the probability of a new match, $q_{t}$, between potential care givers and elders is $q_{t}=0.164$. Substituting the data of Table 1 into Equation (3) and assuming that the natural rate of growth of the group of potential care givers is $n_{t}=0.04$, we get that the rate of "caregivers" in whole population at age over 50 is:

$$
u_{t}=\frac{q_{t}}{q_{t}+s_{t}+n_{t}}=\frac{16.4}{16.4+69.6+4}=18.22 \%
$$

Substituting the data of Table 1 for male, female, in labor force and not in labor force into Equation (3') and assuming that the natural rate of growth of each group of potential care givers is , $n_{t}=0.04$ we get in Table 2 the rate of "caregivers" in the population for each group.

The result for the whole population is lower than reported data from Israel (Brodsky, Resnizky, \& Citron, 2011) [7] which found that $22.5 \%$ of the adult population was acting as informal caregivers for frail elders. Among them, $38 \%$ were between the ages of $44-64$.

Table 1. Transition proportions according to demographic characteristics.

\begin{tabular}{ccc}
\hline Whole population & $\begin{array}{c}\text { End of care Probability } \\
\text { (took care of someone in Wave 1 } \\
\text { Didn't take care of someone in wave 2) }\end{array}$ & $\begin{array}{c}\text { Probability to Start taking care of } \\
\text { someone (didn't take care of someone } \\
\text { in Wave 1 take care in wave 2) }\end{array}$ \\
Male & 69.6 & 16.4 \\
Female & 67.3 & 14.4 \\
In Labor Force & 71.2 & 17.5 \\
Not In Labor Force & 63.4 & 15.3 \\
\hline
\end{tabular}

Table 2. The rate of caregivers.

\begin{tabular}{cc}
\hline & rate of "caregivers" \\
\hline Whole population & $18.22 \%$ \\
Male & $16.80 \%$ \\
Female & $18.88 \%$ \\
In Labor Force & $18.50 \%$ \\
Not In Labor Force & $17.40 \%$ \\
\hline
\end{tabular}


The high end of care rate from treatment points to the existence of a very large substitution among caregivers, mainly among people not in labor force (76.2\%). Additionally, the possibility that in a period where the start taking care rate is low, a larger portion of elders will not be taken care of. A analogous situation has been noticed by researchers who studied the labor market. The findings concerning the labor market pointed to the fact that business cycles are driven primarily by large episodes of job destruction, with relatively stable levels of job creation (e.g., Davis and Haltiwanger (1990, 1992, 1999) [8]-[10], Faberman (2002) [11]). Several researchers emphasized the importance of separations. For example, Blanchard and Diamond (1989, 1990) [12] [13] have found empirical evidence that during recessions the flow out of employment is the main reason for the increase in the unemployment rate, while the decrease in the flow from unemployment into employment has a secondary significance ${ }^{5}$.

\section{Conclusions}

Although there is a large interest in identifying transition probabilities and care rates among various social groups, data about care trajectories, and about the rate of people at age over 50 who are giving care to elders are sparse. In this paper, for the first time, we suggest a theoretical model that will enable the estimation of the proportion of the population engaged in taking care of the aged, among various population groups. Using data for Israel taken from the Survey of Health, Aging and Retirement in Europe (SHARE), we calculated the transition probabilities into and out of care in elder for several population groups.

Our main findings regarding individuals at age over 50 are that probability of start taking care is higher for females while the probability of ending care is higher for males leading to a higher care rate for females $18.9 \%$ comparing to $16.8 \%$ among males. These results are in line with the findings of (Uhlenberg \& Cheuk (2008) [15]; WHO (2002) [1]; UN (2007) [16]) who report that primary caregivers are mostly women.

According to our findings, there is a very high end of care rate from treatment in all population groups, pointing to the existence of a very large substitution among caregivers. The substitution in care is especially large among people out of labor force, whose probability to stop taking care is $76.2 \%$ (comparing to $63.4 \%$ among people in labor force).

\section{Acknowledgements}

This research was supported by an Israeli Science Foundation Grant.

\section{Contribution}

The authors have contributed equally.

\section{References}

[1] World Health Organization (2002) Active Aging: A Policy Framework. WHO, Geneva.

[2] Brodsky, J., Shnoor, Y. and Béer, S. (2014) The Elderly in Israel: Statistical Yearbook. Myers-JDC-Brookdale Institute, Jerusalem.

[3] Lowenstein, A., Katz, R. and Gur-Yaish, N. (2008) Cross-National Variations Infielder Care: Antecedents and Outcomes. Caregiving Contexts: Cultural, Familial and Societal Implications, 93-114.

[4] Pissarides, C. (1984) Efficient Job Rejection. Economic Journal, 94, 97-108. http://dx.doi.org/10.2307/2232658

[5] Mortensen, D. (1982) Property Rights and Efficiency in Mating, Racing, and Related Games. American Economic Review, 72, 968-979.

[6] Diamond, P. (1982) Wage Discrimination and Efficiency in Search Equilibrium. Review of Economic Studies, 49, 217227. http://dx.doi.org/10.2307/2297271

[7] Brodsky, J., Resnizky, S. and Citron, D. (2011) Issues in Family Care of the Elderly: Characteristics of Care, Burden on Family Members and Support Programs. Myers-JDC-Brookdale Institute, Jerusalem.

[8] Davis, S. and Haltiwanger, J. (1990) Gross Job Creation and Destruction: Microeconomic Evidence and Macroeconomic Implications. NBER Macroeconomics Annual, 5, 123-168.

\footnotetext{
${ }^{5}$ Ben David (2005) [14] proved that the separation rate cannot be assumed to be constant and that any change that can affect the economic
} value of a filled job would be followed by a change of separation rate. 
[9] Davis, S. and Haltiwanger, J. (1992) Gross Job Creation, Gross Job Destruction, and Employment Reallocation. The Quarterly Journal of Economics, 57, 819-863. http://dx.doi.org/10.2307/2118365

[10] Davis, S. and Haltiwanger, J. (1999) Gross Flows. In: Ashenfelter, O. and Card, D., Eds., Hand Book of Labor Economics, Vol. 3, Elsevier, 2711-2805.

[11] Faberman, P. (2002) Job Flows and Labor Dynamics in the US Rust Belt. Monthly Labor Review.

[12] Blanchard, O. and Diamond, P. (1989) The Beveridge Curve. Brookings Papers.

[13] Blanchard, O. and Diamond, P. (1990) The Cyclical Behavior of Gross Flows of Workers in the US Brookings Papers on Economic Activity, 1990, 85-143. http://dx.doi.org/10.2307/2534505

[14] Ben David, N. (2005) The Separation Rate Cannot Be Exogenous. Applied Economic Letters, 12, 949-951.

[15] Uhlenberg, P. and Cheuk, M. (2008) Demographic Change and the Future of Informal Caregiving. In: Szinovacz, M.E. and Davey, A., Eds., Caregiving Contexts Cultural, Familial, and Societal Implications, Springer, New York, 9-33.

[16] United Nations (2007) World Population Ageing 2007. United Nations, New York. 